\title{
Retrieval of migrated pancreatic stent: "stent-in-stent" technique
}
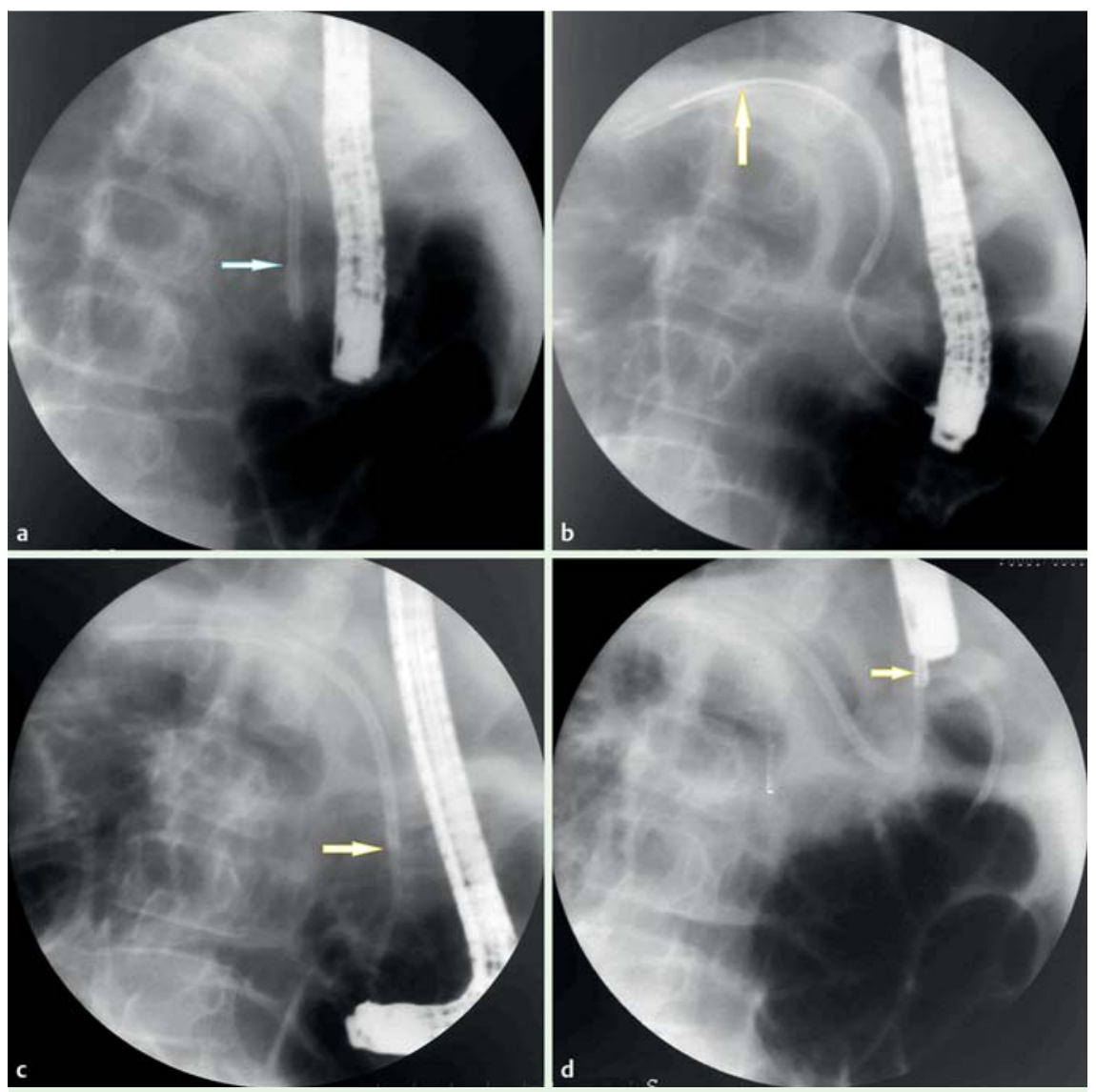

Fig. 1 a Spot image shows the position of a 10-Fr, 10-cm stent, previously placed in a 13-year-old boy for the management of chronic pancreatitis and pain syndrome. The stent has migrated to a position distal to the ampulla (arrow). b The guidewire has been passed across the stent (arrow). c A 7-Fr stent is placed over the guidewire into the native "migrated" stent (arrow). $\mathbf{d}$ The "coaxial" stents are retrieved with a forceps (arrow).

A 13-year-old boy, in whom a 10-Fr, 10-cm pancreatic stent had been placed 3 months earlier to manage chronic pancreatitis and pain syndrome, was admitted for stent exchange. On endoscopic retrograde cholangiopancreatography, the pancreatic stent was not visible at the papilla. The pancreatic duct was cannulated with a 0.025-inch guidewire (VisiGlide; Olympus America, Center Valley, Pennsylvania, USA). Fluoroscopy showed that the stent had migrated deeply into the pancreatic duct and that the guidewire had passed through the stent ( $\bullet$ Fig. 1 a,b).

A novel method for stent retrieval was adopted. After ensuring that the tip of guidewire had passed through the migrated stent, we passed a 7-Fr, 7-cm stent over the guidewire and pushed it into the $10-$ Fr stent. After we confirmed under fluoroscopy that the 7-Fr stent had passed into the $10-$ Fr stent by monitoring the transmission of force through it, we removed the guidewire ( $\bullet$ Fig. 1 c). With the use of a foreign body forceps (Cook Medical, Bloomington, Indiana, USA) and a snare (Olympus, Tokyo, Japan), the 7-Fr/10-Fr stent "system" was withdrawn into the duodenum and finally removed ( $\bullet$ Fig. 1 d).

Pancreatic stents can migrate distally in the pancreatic duct in up to $7.5 \%$ of patients and proximally in $5.2 \%$ of patients. These situations are clinically challenging, and surgical intervention may be required in $10 \%$ to $17 \%$ of cases [ 1 -3]. Experienced endoscopists and dedicated devices are essential to increase the successful endo- scopic retrieval of migrated stents. In practice, the availability of both is limited in many centers. Our novel technique requires only a guidewire and a pancreatic stent of smaller size, which are available in most centers. The chances of trauma to the pancreatic duct are less with this technique than with other techniques, in which an additional device must be accommodated within the pancreatic duct, increasing the likelihood of duct trauma.

Endoscopy_UCTN_Code_CPL_1AK_2AD

Competing interests: None

Yalaka R. Reddy ${ }^{1}$, Harpal S. Dhaliwal' ${ }^{1}$, Pankaj Gupta², Saroj K. Sinha1, Rakesh Kochhar ${ }^{1}$

1 Department of Gastroenterology, Postgraduate Institute of Medical Education and Research (PGIMER), Chandigarh, India

${ }^{2}$ Department of Radiodiagnosis, Postgraduate Institute of Medical Education and Research (PGIMER), Chandigarh, India

\section{References}

1 Johanson JF, Schmalz MJ, Geenen JE. Incidence and risk factors for biliary and pancreatic stent migration. Gastrointest Endosc 1992; 38: $341-346$

2 Lahoti S, Catalano MF, Geenen JE et al. Endoscopic retrieval of proximally migrated biliary and pancreatic stents: experience of a large referral center. Gastrointest Endosc 1998; 47: 486-491

3 Price LH, Brandabur JJ, Kozarek RA et al. Good stents gone bad: endoscopic treatment of proximally migrated pancreatic duct stents. Gastrointest Endosc 2009; 70: 174-179

\section{Bibliography}

DOI http://dx.doi.org/

10.1055/s-0034-1392206

Endoscopy 2015; 47: E339

(c) Georg Thieme Verlag KG

Stuttgart · New York

ISSN 0013-726X

\section{Corresponding author}

\section{Yalaka Rami Reddy, MD}

Department of Gastroenterology

Postgraduate Institute of Medical Education

and Research (PGIMER)

Sector 12

Chandigarh

India, 160012

Fax: $+91-4032213369$

yrrpgi@gmail.com 